\title{
Spatial heterogeneity, biomass and size structure of plankton of the Indian Ocean: some general trends
}

\author{
S. A. Piontkovski ${ }^{1}$, R. Williams ${ }^{2}$, T. A. Melnik $^{1}$ \\ ${ }^{1}$ Institute of Biology of the Southern Seas, 2 Nahimov Pr., Sevastopol 335011, Ukraine \\ ${ }^{2}$ Plymouth Marine Laboratory, Prospect Place, The Hoe, Plymouth PL1 3DH, United Kingdom
}

\begin{abstract}
Data from surveys carried out in 1982 and 1990 in the Arabian Sea, and the South and North Sub-equatorial Divergence regions of the Indian Ocean were used to analyse the spatial distribution and the size spectra of zooplankton in relation to primary production and hydrophysical dynamics on a scale of hundreds of kilometres. Spatial heterogeneity of biomass distributions increased with the size of organisms from phytoplankton to macrozooplankton. The zooplankton abundance spectra changed with hydrodynamic regimes of water dynamics (cyclonic, anticyclonic eddies, frontal zones) and could be approximated by linear regressions in logarithmic scale. From values of the normalised spatial variance of plankton biomass components (phyto-, meso-, macroplankton) it is concluded that heterogeneous 'fields' of predators exist on more uniform 'fields' of prey. Biomass ratios of phytoplankton (chlorophyll a), microzoo-, mesozoo- and macrozooplankton form an inverted pyramid of biomass in the studied regions. Maximal slopes for zooplankton abundance size spectra have been observed in regions of maximum primary production, i.e. in regions of high primary production the smallest zooplankton dominate the total zooplankton. This is also true for regions of high phytoplankton turnover. The ratio of primary production to herbivore production indicates that the highest efficiency of transfer from autotrophs to heterotrophs is carried out by the smaller zooplankton. The ratio of primary production to zooplankton biomass increases as the spectrum slope of the zooplankton abundance increases. This means that the ratio increases when small mesoplanktonic organisms become more dominant amongst the mesoplankton size range. Both types of relationships can be approximated by diminishing non-linear equations. The values of these 2 ratios can change an order of magnitude on a scale of hundreds of kilometres.
\end{abstract}

KEY WORDS: Indian Ocean · Size spectra $\cdot$ Zooplankton biomass

\section{INTRODUCTION}

Before any worthwhile prediction or modelling of the marine pelagic ecosystem can be achieved, an understanding of the functioning and structure of the ecosystem is required. However, it should be noted that there is no well-developed, generally accepted body of theory as to why biomass and productivity of pelagic marine organisms vary greatly in space and time (McGowan 1989). The primary cause is the lack of adequate data on descriptions of the frequency spectra of changes of biological, physical and chemical properties of the system. To understand the consequences of large-scale variations or anthropogenic impacts on biological systems, detailed information is required on the response of pelagic biota to change. It has been demonstrated that changes in one component, or trophic level, of the marine community over several decades can be representative of the 'whole ecosystem' (Aebischer et al. 1990). Therefore it can be concluded that it is not necessary to monitor every variable within the ecosystem and that detailed information of a selection of 'key' variables, over time, could indicate the general patterns of the change within the ecosystem. This implies that a holistic approach is required to sample the marine ecosystem, possibly through the use of some integrative characteristics of the ecosystem structure and variability (Sherman \& Solow 1992).

To derive these system characteristics plankton variability needs to be parameterised. The spatiotemporal variability of plankton communites has been discussed by several authors (Haury et al. 1978, Longhurst 1981, Horne \& Platt 1984, Haury \& Pieper 1988). This embodies one of the main objectives of our work carried out in 
the tropical zone of the Indian Ocean (the Arabian Sea), where one of the largest fish stocks of a single species in the world exists. This species is the myctophid fish Benthosema pterotum and is responsible for an annual production of 100 million tons (GLOBEC 1993). Copepods are the main diet of myctophids in this region (Dalpadado \& Gjosater 1988). However, the spatiotemporal dynamics of fish and copepod populations are little understood for the Indian Ocean.

A further gap in our knowledge of the pelagic ecosystems of this region are trends in planktonic communities' spatiotemporal variability. The International Indian Ocean Expedition highlighted some general properties of spatiotemporal structure and productivity of planktonic communities, typical for the scale of the whole ocean (Rao 1973, 1979). Biological events on a scale from hundreds to tens of kilometres (synoptic and mesoscale variability) are still not well understood. On the other hand, it is known that within this scale in the western part of the Indian Ocean the variability of phyto-, micro- and mesoplankton biomass, as well as primary production, is rather high (Goldberg \& Piontkovski 1985, Kuzmenko \& Georgieva 1985, Kuzmenko 1986, Ostrovskaya 1986, Petipa 1986, Piontkovski et al. 1986). This variability is related to the dynamics of the water masses which are in the form of eddies and fronts. These are well studied for the western part of the Indian Ocean (Kosnyirev \& Shapiro 1981, Plotnikov 1986).

The aim of this paper is to evaluate relationships between some integrative structural and functional characteristics of plankton communities (community size spectrum, primary production, ratio between primary production and biomass of herbivores and carnivores organisms) on a spatial scale of hundreds of kilometres.

\section{MATERIALS AND METHODS}

Sampling of biological and physical variables was carried out during surveys of grids of stations (Fig. 1), at the end of the winter monsoon season (FebruaryMarch, 1982 and 1991) from the RV 'Professor Vodyanitsky'. The spatial resolution of sampling within the grids was approximately $50 \mathrm{~km}$. There were usually about 50 stations within each grid and the data from 4 of these grids surveys were used in this study. Measurements of CTD profiles (Plotnikov 1986, Martynenko et al. 1991), primary production and chlorophyll a (chl a) (Kovaleva \& Kuzmenko 1986, Kuzmenko 1986, 1991, Yunev 1991), abundance and biomass of microzooplankton (Ostrovskaya 1986, Skryabin 1991), mesozooplankton (Piontkovski et al. 1986, Melnik 1991), and macrozooplankton (Ignatyev 1991) were taken at each station from the surface to $100 \mathrm{~m}$. At Grids 34 and 35, biological sampling was conducted mainly at night, while day sampling was used on the remaining grids.

Samples for chl a determination were collected by means of water bottles at 4 to 7 depths within the 0 to 100 or 0 to $150 \mathrm{~m}$ layers. Water was filtered through Synpor filters $(1.5 \mu \mathrm{m})$ and chl a concentration measured from $90 \%$ acetone extracts using a spectrophotometer.

The Juday Plankton Nets (mesh size 112 to $142 \mu \mathrm{m}$ ) were used for mesozooplankton vertical hauls. The wet weight of samples was measured on board ship using a WT-500 balance $( \pm 0.1 \mathrm{mg})$. Composition of zooplankton was determined back at the laboratory from stored $4 \%$ buffered formalin samples. Aliquots $(1 \mathrm{ml})$ were taken from the samples using Stempel pipettes until sufficient numbers of organisms were counted. Measured body lengths of individual mesozooplankton (around 100 to 200 individuals for each range) were classified into 11 size ranges: <0.5, $0.5-0.75, \quad 0.75-1.0,1.0-1.25,1.25-1.50,1.50-1.75$, $1.75-2.0,2.0-3.0,3.0-4.0,4.0-6.0$, >6.0 mm. Zooplankton abundance size spectra were then determined on the basis of these size ranges. Therefore, our definition of community size spectrum is the abundance/biomass distribution of individuals over their range of body sizes.

Regression analysis has been used to investigate links between characteristics of community size spectra and primary production (standard statistical software: Statview SE+Graphics for Macintosh users). Linear regressions were used for zooplankton abundance size spectra approximations (as a function of body length) and $\ln (x+1)$-transformation applied to both axes.

When sampling throughout the $24 \mathrm{~h}$ period, the diel variations of zooplankton biomass need to be taken into account. The diel trend was elucidated from measurements of abundance and biomass taken from the long-term drift station and from the other short-term stations within the grids. In the latter case, data were allocated into twelve $2 \mathrm{~h}$ periods. The trend was used to correct the biomass values and to compute 'day' and 'night' maps of zooplankton biomass spatial distribution. The maps were used for comparisons between regions. It should be noted that 'day' and 'night' biomass values differed by 1.5 to 2.5 times.

Macrozooplankton biomass was obtained from oblique tows with mid-water trawls (mouth area $0.25 \mathrm{~m}^{2}$, mesh size $750 \mu \mathrm{m}$ ) in the 0 to $100 \mathrm{~m}$ layer. The upper size limit of organisms taken from these trawls was around $50 \mathrm{~mm}$ (Ignatyev 1991).

Our aim was to amalgamate all collected data in order to analyse the size spectra of the whole community and determine spectra characteristics and rela- 
Fig. 1. Station grids in the Arabian Sea (Grids 34 and 35), in the region of the North Subequatorial Divergence (Grid 7) and in the region of the South Sub-equatorial Divergence (Grid 6) together with dynamical topography. (a) Location of grids; (b) dynamical heights (in dynamic $\mathrm{cm}$ ) of the Arabian Sea survey for the layer 0 to $150 \mathrm{~m}$ (Martynenko et al. 1991); (c) dynamical heights (in dynamic $\mathrm{mm}$, related to surface $1000 \mathrm{db}$ ) of the North Subequatorial Divergence for the surface $(0 \mathrm{~m})$, after Plotnikov (1986); (d) dynamical heights (in dynamic mm, related to surface $1000 \mathrm{db}$ ) of the South Subequatorial Divergence for the surface $(0 \mathrm{~m})$, after Plotnikov (1986)
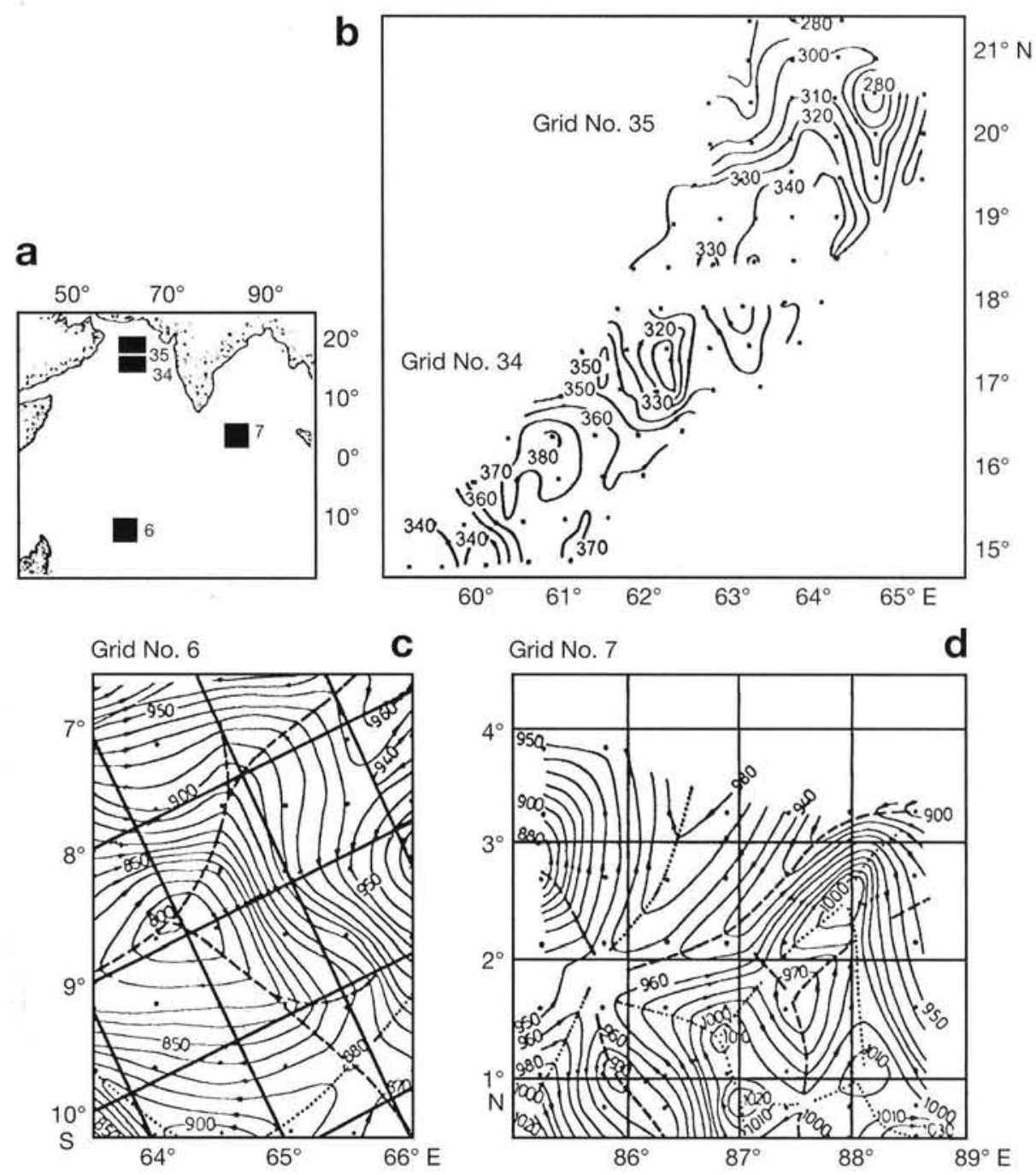

tionships to primary production. Biomass ratios of the plankton community for all groups (approximate size range from $5 \mu \mathrm{m}$ to $50 \mathrm{~cm}$ ) were expressed in $\mathrm{mg} \mathrm{m}^{-3}$ (wet wt) for the 0 to $100 \mathrm{~m}$ layer.

To compare some characteristics of the structure and functioning of the secondary production within the plankton community the herbivore and carnivore species were counted. The species were differentiated according to their dominant feeding strategy and from published studies of feeding behaviour (Petipa et al. 1971, Samyishev 1971, 1973, Timonin 1973, Pavlovskaya et al. 1975, Greze \& Moryakova 1984). Calculations of secondary production were carried out on the basis of herbivorous biomass size spectra and from estimations of herbivorous species specific production from the western part of the Indian Ocean, carried out by Sajina (1986) for the same monsoon period. The ratio of primary to herbivore production was also estimated.

\section{RESULTS AND DISCUSSION}

\section{Hydrophysical dynamics of waters}

Typical features of the mesoscale dynamics of the 4 studied regions ( 2 grids in the Arabian Sea, and 1 each in the South and North Sub-equatorial Divergence regions) are densely packed eddy fields. The structure of surface waters exhibit a well-developed field of interacting cyclonic and anticyclonic eddies and frontal zones (Fig. 1). It is well documented that the vertical component of water flows is directed upward in cyclonic eddies, with a counter-clockwise rotation (in the north hemisphere) and directed downward in anticyclonic eddies (Plotnikov 1986, Martynenko et al. 1991). As a consequence of these dynamics, cold water is observed in the centre of the cyclonic eddies, while warmer waters occur in centres of anticyclonic eddies. The horizontal dimensions of these eddies were in the 
range of 100 to $150 \mathrm{~km}$ (Grids 34 and 35) and vertically they were measured to depths of several hundred metres. In the Arabian Sea, eddies exhibit slow latitudinal oscillations. At Grid 34, the velocity of such oscillations was around 0.9 to $2.8 \mathrm{~km} \mathrm{~d}^{-1}$. Frontal zones form at the boundaries of these eddies. Maximum current velocities were observed at the surface with velocities declining from south to north: 40 to $25 \mathrm{~cm} \mathrm{~s}^{-1}$ in the southern currents and 34 to $23 \mathrm{~cm} \mathrm{~s}^{-1}$ in the northern direction currents. At Grids 34 and 35, the general water mass transport was dominated by macroscale northeastern transport. The presence of eddy fields causes considerable variance in the basic structural characteristics of the water masses. For example, within the area of Grid 34 the thickness of the surface mixed layer changed from $25 \mathrm{~m}$ in regions of local upwelling to $115 \mathrm{~m}$ in convergence zones.

A number of different processes may give rise to solitary eddies or an eddy field. In the Indian Ocean, many eddies are probably formed by Rossby waves during the meandering of the macroscale frontal zone and its decay in the intermonsoon period (Kosnyirev \& Shapiro 1981). In this case, the process of eddy formation occurs during the passage of a wave and the isopycnal surfaces must be deflected upward with a consequent uplifting of the nutricline. The water is not permanently upwelled, but the uplifted zone travels with the wave. Since the duration of influence of such an uplifted water mass, at any location, is of the order of $10 \mathrm{~d}$, phytoplankton may receive a nutrient pulse and consequently bloom. The response of the zooplankton community to such a perturbation is likely to be small, because the generation time for zooplankton (for example, for copepods of the Indian Ocean tropical zone) is 1.5 to 3 times longer at approximately 15 to $30 \mathrm{~d}$. This can be the case even when the concentration of food for herbivorous and carnivorous species is very high (Sajina 1986).

Another cause of eddy field generation is the baroclinic instability of coastal currents of the Somalian and Arabian coasts. These coastal currents can generate eddies which subsequently move into the open ocean. Such eddies, moving from the Somalian coast, have been observed by satellites (Golovastov et al. 1982). On the basis of measurements taken during our expeditions, it was shown that some of them may have temperature-salinity characteristics of Arabian upwelled water, which provides evidence for their meridional motion from north to south (Kosnyirev \& Shapiro 1981). Well-known CZCS images on chl a macrospatial distribution within the Arabian Sea region also support the event of water mass transport from the coastal to the open ocean region.

In the area of the South Sub-equatorial Divergence (Grid 6), the Equatorial Counter Current (enriched by nutrients but low in oxygen, typical of the Arabian Water Mass) interacted with the South Passat Current (enriched with oxygen but low in nutrients, typical of the Subsurface Subtropical Water Mass). It was concluded from measurements taken at the long-term buoy station that the average current geostrophic velocity in the surface layer was about $50 \mathrm{~cm} \mathrm{~s}^{-1}$. Baroclinic instability of interacting currents caused the formation of the intensive cyclonic eddy, which occupied nearly all of the grid. Edges of smaller anticyclonic eddies were monitored on the periphery of the studied region (see Fig. 1). Dynamical structures observed on the surface have been detected to depths of $800 \mathrm{~m}$. The position of the South Sub-equatorial Divergence in this region coincided with the orientation of the latitudinal axis of the cyclonic eddy and is shown by the divergence lines.

The area of the North Sub-equatorial Divergence (Grid 7) which was studied was located within the region of alternatively directed and interacting currents. Measurements from the long-term buoy station, in the northeastern area of the grid, showed an average velocitiy in the upper $30 \mathrm{~m}$ layer of approximately $65 \mathrm{~cm} \mathrm{~s}^{-1}$. Water dynamics of this area were determined by the westerly directed North-Eastern Monsoon Current (carrying the Bengal Bight Water Mass) and the Equatorial Counter Current (carrying the Subsurface Arabian Water Mass, from west to east). The coastal waters of the Timor Sea were entrained into this region from the southeast. The interactions of several different water masses caused a complicated system of eddies and meanders (see Fig. 1d). Such macroscale events as the North Sub-equatorial Divergence separate the Bengal Bight Water Mass from waters having subtropical structure (Plotnikov 1986).

\section{Spatial distribution and variability of planktonic community components}

Spatial distributions of zooplankton biomass within the grid surveys were quite heterogeneous (Fig. 2). For example, in Grid 35, mesozooplankton biomass within the integrated layer 0 to $100 \mathrm{~m}$ varied within the range of 114 to $516 \mathrm{mg} \mathrm{m}^{-3}$ and in Grid 34 from 164 to $594 \mathrm{mg}$ $\mathrm{m}^{-3}$. In regions of the North and the South Subequatorial Divergence (Grids 7 and 6 respectively), average values were 2 to 3 times less than that in the Arabian Sea. Maximal values have been observed at the periphery of eddies, as well as in the macroscale frontal zones. The location of phytoplankton, mesozooplankton and macrozooplankton biomass peaks did not, as a rule, spatially coincide. They were shifted relative to each other and this spatial shift was from tens to hundreds of kilometres. This tendency was less pro- 

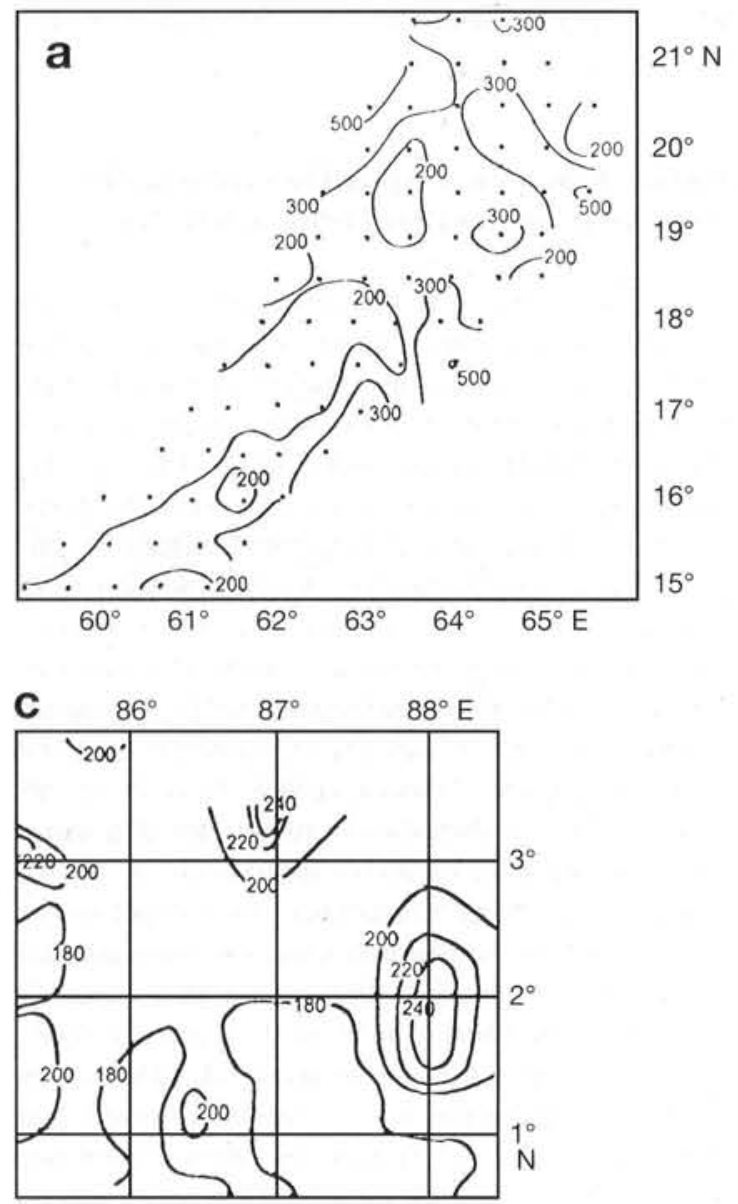

nounced in the Arabian Sea. Low cross-correlation values between phyto-, meso- and macrozooplankton biomass for each area also indirectly confirm this spatial shifting. However, when discussing spatial shifts, we have to realise that the maps of dynamical topography (i.e. system of currents) are based on many theoretical assumptions, i.e. the method of mapping topography is quite rough. These make a comparison of the dynamic topography maps with those of zooplankton distributions very approximate.

On the other hand, data from the grids can provide sufficient information on average values of spatial variance of the plankton components. A comparison of spatial heterogeneity of zooplankton with other components of the plankton community and environmental variables has been attempted quantitatively. The data on chl a, and micro-, meso- and macrozooplankton biomass from Grids 34 and 35 were amalgamated (surveys were conducted one after another) and the spatial heterogeneity of fields was represented in a form of normalised spatial variance $\left(S^{2} / x\right)$ for the whole area (Table 1). From this table it can be seen that a hierarchy of heterogeneity exists; the heterogeneity of spa-

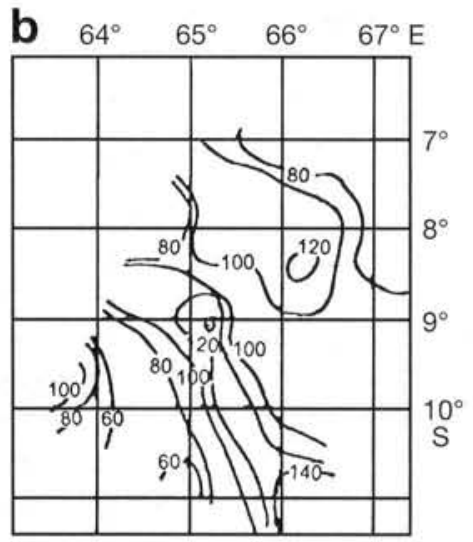

Fig. 2. Spatial distribution of zooplankton biomass $\left(\mathrm{mg} \mathrm{m}^{-3}\right.$, wet wt, 0 to $100 \mathrm{~m}$ layer) in studied regions. (a) Arabian Sea (Grids 34 and 35); (b) South Sub-equatorial Divergence region (Grid 6); (c) North Sub-equatorial Divergence region (Grid 7)

tial distribution increases with the size of the organisms, from phytoplankton (chl a) through mesozooplankton to macrozooplankton.

The normalised spatial variance $\left(S^{2} / x\right)$ of various characteristics of an ecosystem is often used as a measure of 'patchiness' of spatial distribution (Okubo 1980, Piontkovski et al. 1986). From a trophodynamics viewpoint, the increase of the $S^{2} / x$ value means that relatively heterogeneous fields of predators exists on more uniformly distributed fields of their prey. This tendency can be observed throughout the trophic levels. Differences in 'intensity of heterogeneity' among the principal structural characteristics of the community and the environment perhaps explain the reason for low cross-correlations in spatial distribution of phyto-, micro-, meso- and macrozooplankton, on a scale of hundreds of kilometres, noted in field studies in tropical regions (Piontkovski 1985, Piontkovski \& Baev 1990).

\section{Patterns of the community size spectrum}

On the level of 'coarse' estimates of community size spectrum, there is a trend of increasing biomass from phytoplankton (chl a) through micro- and mesozoo-

Table 1. Characteristics of macroscale spatial heterogeneity of fields of different variables in the upper 0 to $100 \mathrm{~m}$ in the Arabian Sea. $S^{2}$ : spatial variance; $x$ : mean; CV: coefficient of variation

\begin{tabular}{|lcr|}
\hline Type of field & \multicolumn{1}{c|}{$S^{2} / x$} & $\mathrm{CV}$ \\
\hline Temperature & 0.02 & 2.91 \\
Salinity & 0.005 & 0.36 \\
Chlorophyll a biomass & 0.02 & 30.57 \\
Microzooplankton biomass & 1.54 & 30.91 \\
Mesozooplankton biomass & 48.39 & 43.17 \\
Macrozooplankton biomass & 1003.3 & 226.52 \\
\hline
\end{tabular}


Table 2. Statistical characteristics of plankton spatial distributions, $S^{2} / X$ : spatial variance

\begin{tabular}{|lcccc|}
\hline Parameter & Grid 34 & Grid 35 & Grid 6 & Grid 7 \\
\hline Chlorophyll $a$ & & & & \\
Mean & 0.21 & 0.2 & 0.18 & 0.18 \\
SD & 0.05 & 0.06 & 0.13 & 0.13 \\
$\mathrm{n}$ & 39 & 37 & 46 & 46 \\
$S^{2} / \mathrm{x}$ & 0.01 & 0.02 & 0.09 & 0.09 \\
Microzooplankton & & & & \\
Mean & 16.7 & 17 & 12.29 & 8.84 \\
SD & 5.68 & 5.44 & 3.27 & 2.26 \\
$\mathrm{n}$ & 38 & 38 & 47 & 50 \\
$S^{2} / \mathrm{X}$ & 1.93 & 1.74 & 0.87 & 0.58 \\
Mesozooplankton & & & & \\
Mean & 216.8 & 298.5 & 97.8 & 77.4 \\
SD & 86.7 & 128.4 & 41.1 & 26.06 \\
$\mathrm{n}$ & 52 & 56 & 47 & 47 \\
$S^{2} / x$ & 34.67 & 55.23 & 17.27 & 8.77 \\
Macrozooplankton & & & & \\
Mean & 222.5 & 101.6 & & \\
SD & 505.1 & 139.2 & & \\
$\mathrm{n}$ & 27 & 28 & & \\
$S^{2} / \mathrm{x}$ & 1146.63 & 190.71 & & \\
\hline
\end{tabular}

plankton to macrozooplankton (Table 2). This trend looks statistically sustainable for the area of Grid 34 . However, the northern grid (35) has average macrozooplankton biomass values less than those of mesozooplankton. The above tendency is valid for the sequence 'phyto-, microzoo-, mesozooplankton' for all studied regions and indicates the phenomenon of the 'inverted pyramid of biomass' within epiplankton communities. Such biomass ratios do not fit Sheldon's general concept (Sheldon et al. 1972) that the total biomass of organisms, in logarithmically equal size ranges, should be constant. Even if we should convert biomass into logarithmically equal size ranges, it would not change the qualitative tendency of increasing average values. The 'inverted' pyramid of average biomass of different size ranges can be shown from our data. Enhanced values of zooplankton biomass compared with those of phytoplankton have been observed for other regions of the tropical Atlantic Ocean (Greze et al. 1984), and Holligan et al. (1984) reported an inverted pyramids of organic carbon biomass for epiplanktonic community of the English Channel stratified waters.

In contrast with the 'coarse' community size spectra, the behaviour of the fine spectra (the internal structure of mesozooplankton size range only) fits the above concept. The fine structure of zooplankton abundance size spectra has been analysed for different hydrodynamic situations in Grids 34 and 35. The statistical data analysis confirmed that the size spectra could be approximated by linear regressions in logarithmic units (Fig. 3). The curves indicate that decreasing abundance is proportional to increasing size of the individuals.

\section{Relationships between plankton community structural and functional characteristics}

It is noted from above that the size spectra curves are not constant and that they exhibit a variability in the range -0.8 to -1.8 . Correlation analysis showed a statistically significant relationship between the slope of the curve and primary production values (Fig. 4). The maximum slopes of zooplankton size spectra have been observed in regions with highest values of primary production. Consequently, in regions with high values of primary production, zooplankton organisms of the smallest size range dominate the total zooplankton abundance. The 'fine' scale community size spectra are similar to those from tropical Atlantic and the Pacific Ocean regions (Tseitlin 1986, Zyev \& Piontkovski 1990). The relationship between spectra slope and primary production explains about $60 \%$ of spectra slope's variability, which means that other structural or functional properties of the ecosystem should also be considered. We assume that these properties can be expressed as ratios. One ratio is that of primary production $(P P)$ to zooplankton biomass $\mathrm{Bz}$ (the latter being expressed in carbon units). This $P P / B z$ ratio has the dimension of $\mathrm{d}^{-1}$ and shows the turnover rate of phytoplankton through zooplankton biomass, i.e. it is a measure of efficiency with which primary production is utilized by zooplankton (Vinogradov \& Shushkina 1987). The implication from this type of relationship (Fig. 5a) is that, in regions where phytoplankton turnover rate is high, the zooplankton is mainly represented by smaller organisms; their contribution to total

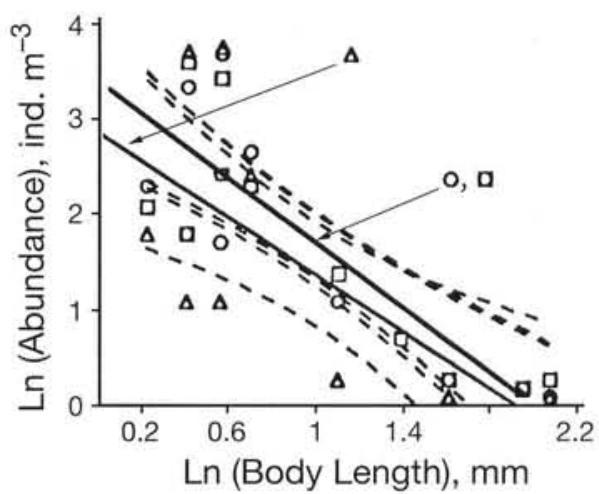

Fig. 3. Size spectra of zooplankton represented as regressions of $\ln$ (Abundance) against $\ln$ (Body length) in the 0 to $100 \mathrm{~m}$ depth layer from cyclonic eddies $(O)$, frontal zone $(\square)$ and anticyclonic eddies $(\Delta)$ of the Arabian Sea (Grids 34 and 35). Average regression: $y=3.72-1.87 x ; r^{2}=0.78 ; p=0.01$ 


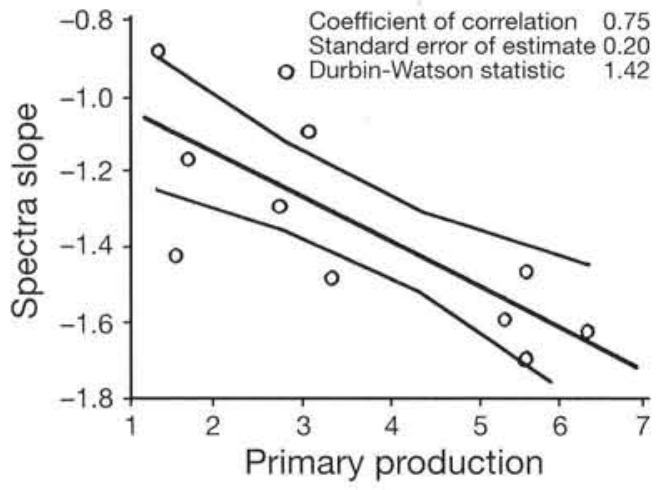

Fig. 4. Relationship between zooplankton community size spectra slopes and primary production $\left(\mathrm{mg} \mathrm{C} \mathrm{m}^{-3} \mathrm{~d}^{-1}\right.$, for $100 \mathrm{~m}$ layer) in the Arabian Sea (Grids 34 and 35)

abundance of individuals considerably exceeds that of larger organisms. In regions with low phytoplankton turnover rate, the contribution of large zooplankton organisms becomes more significant.

The ratio of primary production to the biomass of the total zooplankton community has been considered as a measure of biomass renewal within the ecosystem (Margalef 1968, Odum 1971, Vinogradov \& Shushkina 1987). In these terms, it has been noted that in young ecosystems, such as upwelling regions, the energy is not used efficiently, because a larger quantity of energy is used per unit of biomass (i.e. the specific energy flux is high). In contrast, in mature systems the specific energy flux is low. These conclusions were derived by Vinogradov \& Shushkina (1987) from the comparison of ecosystems on a global scale. Our data show that similar structural-functional integrative ratios exhibit quite high variability on meso/synoptic scales. In regions of highly packed eddy fields, such as the northern Indian ocean, the $P P / B z$ ratio can actually change an order of magnitude over hundreds of kilometres.

A second parameter, the ratio of primary production to herbivore production $(P P / P h)$, can be interpreted as the contribution of phytoplankton primary production to herbivore production. This relationship indicates that in areas where the efficiency of transformation of matter from autotrophic to the first heterotrophic level is highest, it is carried out by the smallest organisms of the whole zooplankton size range (Fig. 5b). At the same time, there is a critical value of the $P P / P h$ ratio where no change in the size of zooplankton occurs above the value. This is where the decreasing curve perhaps reaches a plateau, although the 'plateau part' of the curve is not well fitted by data. The $P P / P h$ ratio (or its inverse ratio, the ecological efficiency coefficient) as well as the $P P / B z$ ratio can change an order of magnitude. They exhibit similar variance when plank-
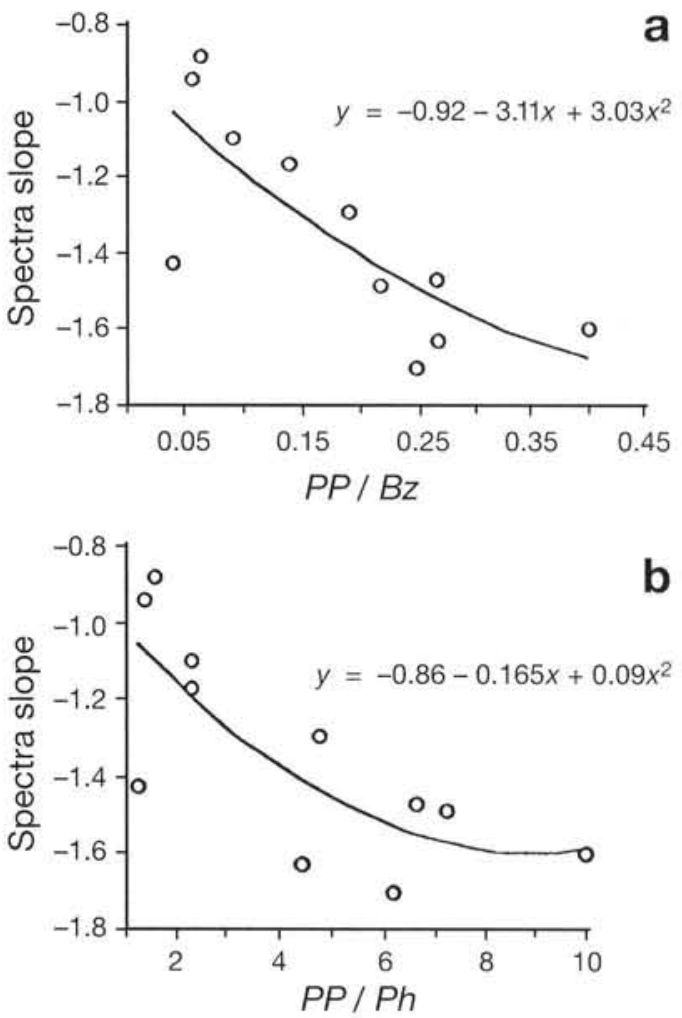

Fig. 5. Relationships between structural and functional characteristics of plankton communities (for the layer 0 to $100 \mathrm{~m}$ ) of the Arabian Sea (Grids 34 and 35): (a) primary production $(P P) /$ zooplankton biomass $(B z)$; (b) primary production $(P P) /$ herbivore production $(P h)$

tonic communities from different productive regions and different oceans, such as the Indian Ocean and the Atlantic Ocean (Vinogradov \& Shushkina 1987), are compared. This implies that the main structural-functional integrative ratios of ecosystems are comparable by their variance at meso-, macro- and megascales. In consequence, to obtain accurate averaged estimates of the structural or functional characteristics of planktonic ecosystems on a macroscale depends greatly on the mesoscale sampling strategy used. Mesoscale sampling with further subsequent smoothing of this estimates over large areas (squares) should precede global generalisations.

\section{Summary}

In regions with well-developed eddy fields, there is a trend of increasing macroscale spatial heterogeneity from phyto-, through micro- to mesozooplankton biomass. Within this coarse scale sequence of plankton community size spectrum the values for the average biomass increase. The formation of a particular zoo- 
plankton community size structure may be related to several basic structural-functional ratios such as $P P / B Z$ and $P P / P h$ and values of primary production.

Acknowledgements. We are very obliged to our colleagues: L. V. Kuzmenko, T. M. Kovaleva, L. V. Georgieva, S. Martynenko, V. Skryabin, N. A. Ostrovskaya and S. M. Ignatyev (IBSS, Sevastopol), whose data were used in the analysis. The writing of this manuscript was carried out under a grant from the Royal Society, United Kingdom.

\section{LITERATURE CITED}

Aebischer, N. J., Coulson, J. C., Colebrook, J. C. (1990). Parallel long term trends across four marine trophic levels and weather. Nature 347: 753-755

Arashkevich, E. G., Timonin, A. G. (1970). Feeding of copepods of the tropical part of the Pacific Ocean. Reports of USSR Academy of Science (Dokladyi Akademii Nauk SSSR) 191(4): 935-938 (in Russian)

Dalpadado, P., Gjøsæter, J. (1988). Feeding ecology of the lanternfish Benthosema pterotum from the Indian Ocean. Mar. Biol. 99: 555-567

GLOBEC (1993). Report No. 9. Implementation plan and Workshop report for U.S. GLOBEC studies in the Arabian Sea. Sci. Steer. Comm. Coord. Office, Univ. of California, Davis

Goldberg, G. A., Piontkovski, S. A. (1985). Spatial-temporal structure of mesoplankton field of the Indian Ocean tropical zone surficial layer. Ecology of the Sea (Ekologiya Morya) 19: 86-110 (in Russian)

Golovastov, V. A., Pokudov, V. V., Tunegolovetzs, V. P., Holmanov, V. P. (1982). Pecularities of thermodynamics and structure of waters of the Indian Ocean Tropical Zone. In: The first experiment PIGAP (Pervyi experiment PIGAP). Vol. 4. Hydrometeoizdat, Leningrad (in Russian)

Greze, V. N., Kovalev, A. V., Lebedeva, M. N. (1984). General structural and functional characteristics of southern Atlantic anticyclonic circulation as an ecological system. In: Greze, V. N. (ed.) Bioproductional system of the large scale oceanic circulation (Bioprodukcionnaya sistema krupnomaschtabnogo okeanicheskogo krygovorota). Naukova Dumka, Kiev (in Russian)

Greze, V. N., Moryakova, V. K. (1984). Size composition and trophic structure. In: Greze, V. N. (ed.) Bioproductional system of the large scale oceanic circulation (Bioprodukcionnaya sistema krupnomaschtabnogo okeanicheskogo krygovorota). Naukova Dumka, Kiev (in Russian)

Haury, L., McGowan, J. A., Wiebe, P. H. (1978). Patterns and processes in the time-scales of plankton distributions. In: Steele, J. H. (ed.) Spatial patterns in plankton communities. Plenum Press, New York, p. 277-327

Haury, L., Pieper, R. E. (1988). Zooplankton: scales of biological and physical events. In: Soule, D. F., Kleppel, G. S. (eds.) Marine organisms as indicators. Springer-Verlag, New York, p. 35-73

Holligan, P. M., Harris, R. P., Newell, D. S., Harbour, R. N., Head, R. N., Linley, E. A. S., Lucas, M. I., Tranter, P. R. G., Weekley, C. M. (1984). Vertical distribution and partitioning of organic carbon in mixed, frontal and stratified waters of the English Channel. Mar. Ecol. Prog. Ser. 14: $111-127$

Horne, P. W., Platt, T. (1984). The dominant space and time scales of variability in the physical and biological fields on continental shelves. Rapp. P.-v. Réun. Cons. int. Explor.
Mer 183: 8-19

Ignatyev, S. M. (1991). Cruise report on 30th expedition of R/V 'Professor Vodyanitsky'. Archives of the Institute of Biology of the Southern Seas, Sevastopol (in Russian)

Kosnyirev, L. V., Shapiro, N. B. (1981). Synoptical variety of the Indian Ocean North-West part. Preprint. Marine Hydrophysical Institute, Sevastopol (in Russian)

Kovaleva, T. M., Kuzmenko, L. V. (1986). Vertical distribution and diel changes of phytoplankton. In: Petipa, T. S. (ed.) Ecological systems in active dynamical zones of the Indian Ocean (Ekologicheskie sistemyi aktivnyih dinamicheskih zon Indiiskogo Okeana). Naukova Dumka, Kiev, p. 64-69 (in Russian)

Kuzmenko, L. V. (1986). The primary production: distribution and diurnal dynamics. In: Petipa, T. S. (ed.) Ecological systems in active dynamical zones of the Indian Ocean (Ekologicheskie sistemyi aktivnyih dinamicheskih zon Indiiskogo Okeana). Naukova Dumka, Kiev, p. 69-79 (in Russian)

Kuzmenko, L. V. (1991). Cruise report on 30th expedition of R/V 'Professor Vodyanitsky'. Archives of the Institute of Biology of the Southern Seas, Sevastopol (in Russian)

Kuzmenko, L. V., Georgieva, L. V. (1985), Phytoplankton production of the north-western part of the Indian Ocean at spring period. Ecology of the Sea (Ekologiya Morya) 19: 32-40 (in Russian)

Longhurst, A. R. (1981). Significance of spatial variability. In: Longhurst, A. R. (ed.) Analysis of marine ecosystems. Academic Press, London, p. 415-442

Margalef, R. (1968). Perspectives in ecological theory. Chicago Univ. Press, London

Martynenko, S., Volkov, N., Jarov, N. (1991). Cruise report on 30th expedition of R/V 'Professor Vodyanitsky'. Archives of Institute of Biology of the Southern Seas, Sevastopol (in Russian)

McGowan, J. A. (1989). Pelagic ecology and Pacific climate. In: Peterson, D. H. (ed.) Aspects of climate variability in the Pacific and Western Americas. Geophysical Monogr. Am. geophys. Union 55 : 141-150

Melnik, T. A. (1991). Cruise report on 30th expedition of R/V 'Professor Vodyanitsky'. Archives of the Institute of Biology of the Southern Seas, Sevastopol (in Russian)

Odum, E. P. (1971). Fundamentals of ecology. Sanders, Philadelphia

Okubo, A. (1980). Diffusion and ecological problems: mathematical models. Biomathematics, 10. Springer Verlag, New York

Ostrovskaya, N. A. (1986). Microzooplankton: distribution and diurnal dynamics. In: Petipa, T. S. (ed.) Ecological systems in active dynamical zones of the Indian Ocean (Ekologicheskie sistemyi aktivnyih dinamicheskih zon Indiiskogo Okeana). Naukova Dumka, Kiev, p. 110-122 (in Russian)

Pavlovskaya, T. V., Pavlutin, A. P., Afrikova, S. G., Tzareva, L. V. (1975). Feeding and energy transformation of the consumed food among abundant forms of tropical plankton. In: Expeditional studies in the south Atlantic and the Mediterranean Sea (Ekspedicionnye issledovaniya $\mathrm{v}$ yujnoi Atlantike i Sredizemnom more). Naukova Dumka, Kiev, p. 181-191 (in Russian)

Petipa, T. S. (1986). Ecological systems in active dynamical zones of the Indian Ocean. In: Petipa, T. S. (ed.) Ecological systems in active dynamical zones of the Indian Ocean (Ekologicheskie sistemyi aktivnyih dinamicheskih zon Indiiskogo Okeana). Naukova Dumka, Kiev, p. 69-79 (in Russian)

Petipa, T. S., Pavlova, E. V., Sorokin, Yu. I. (1971). Investiga- 
tion of feeding of abundant plankton forms of the Pacific Ocean tropical region by the radio-carbon method. In: Functioning of pelagic communities of the tropical ocean regions (Fynkcionirovanie pelagicheskih soobshestv tropicheskih raionov okeana). Nauka, Moscow, p. 123-150 (in Russian)

Piontkovski, S. A. (1985). Statistical estimates of mesoscale structure of biological fields of tropical zone and their relationships with fields of physical and chemical elements. Pol. Arch. Hydrobiol. 32(3/4): 357-370

Piontkovski, S. A., Baev, S. A. (1990). The relationship between biological and hydrophysical fields in the eastern part of the tropical Atlantic. In: The ocean-cosmos: the experiment 'Atlantic-89' (Okean-Kosmos. Eksperiment 'Atlantika-89'). Deponent of VINITI No. 4496-B90, Sevastopol, p. 150-165 (in Russian)

Piontkovski, S. A., Melnik, T. A. Scherbatenko, P. V. (1986). Temporal variability in mesozooplankton distribution. In: Petipa, T. S. (ed.) Ecological systems in active dynamical zones of the Indian Ocean (Ekologicheskie sistemyi aktivnyih dinamicheskih zon Indiiskogo Okeana). Naukova Dumka, Kiev, p. 189-205 (in Russian)

Plotnikov, V. A. (1986). Temperature-salinity and dynamical structure of waters in the subequatorial regions of the Indian Ocean. In: Petipa, T. S. (ed.) Ecological systems in active dynamical zones of the Indian Ocean (Ekologicheskie sistemyi aktivnyih dinamicheskih zon Indiiskogo Okeana). Naukova Dumka, Kiev, p. 18-46 (in Russian)

Rao, T. S. S. (1973). Zooplankton studies in the Indian Ocean. In: Zeitschel, B. (ed.) The biology of the Indian Ocean. Springer-Verlag, Berlin, p. 243-255

Rao, T. S. S. (1979). Zoogeography of the Indian Ocean. In: Van der Spoel, S., Pierrot-Bults, A. C. (eds.) Zoogeography and diversity in plankton. Bunge, Utrecht, p. 254-292

Sajina, L. I. (1986). Copepods, fecundity and production. In: Petipa, T. S. (ed.) Ecological systems in active dynamical

This article was submitted to the editor zones of the Indian Ocean (Ekologicheskie sistemyi aktivnyih dinamicheskih zon Indiiskogo Okeana). Naukova Dumka, Kiev, p. 150-160 (in Russian)

Samyishev, E. Z. (1971). Feeding of some abundant species of copepods in the Guinean Bay. Proceedings of Atlant NIRO (Trydi ATLANTNIRO) 37: 216-271 (in Russian).

Samyishev, E. Z. (1973). The ratio of trophic groups of copepods in zooplankton of the Guinean Bay. Hydrobiol. J. (Hydrobiologicheskii Jyrnal) 9(4): 32-41 (in Russian)

Sheldon, R. W., Prakash, A., Sutcliffe, W. H. Jr (1972). The size distribution of particles in the ocean. Limnol. Oceanogr. 17: $327-340$

Sherman, K., Solow, A. R. (1992). The changing states and health of a large marine ecosystem. Comm. Meet. int. Coun. Explor. Sea C.M.-ICES L:38: 1-31

Skryabin, V. (1991). Cruise report on 30th expedition of R/V 'Professor Vodyanitsky'. Archives of the Institute of Biology of the Southern Seas, Sevastopol (in Russian)

Timonin, A. G. (1973). Structure of pelagic communities. Trophic structure of zooplanktonic communities of the northern part of the Indian Ocean. Oceanology (Okeanologiya) 13 (1): 114-124 (in Russian)

Tseitlin, V. B. (1986) The energetics of the deep-sea pelagic communities. Vinogradov, M. E. (ed.) Nauka, Moscow (in Russian)

Vinogradov, M. E., Shushkina, E. A. (1987). The functioning of the ocean epipelagic planktonic communities. Nauka, Moscow (in Russian)

Yunev, O. A. (1991). Cruise report on 30th expedition of R/V 'Professor Vodyanitsky'. Archives of the Institute of Biology of the Southern Seas, Sevastopol (in Russian)

Zyev, G. V., Piontkovski, S. A. (1990). Structural-functional characteristics of the epipelagic ecosystems. In: Zyev, G. V. (ed.) The productivity of the Equatorial Atlantic (Produktivnost ekvatorialnoi Atlantiki). Naukova Dumka, Kiev (in Russian)

Manuscript first received: March 28, 1994

Revised version accepted: September 30, 1994 